\title{
AN ECONOMIC FRAMEWORK FOR CHOOSING AMONG LAND USES
}

\section{By ANTHONY SCOTT ${ }^{1}$}

\section{INTRODUCTION}

When we get down to the task of choosing one use of land over another, there is a tremendous need for detailed information.

The question arises, however, how all this information is to be used. Once all the facts are known, what is to be done with them? Further, how can we avoid collecting a lot of useless information, and get on with the job of decision?

The role of economics is to provide a framework on which the data can be hung, and on which certain kinds of information will become conspicuous by their absence. The purpose of this paper is to sketch this framework. To most foresters it will be familiar. There are no new ideas in this field. The reason is perhaps that both farm and forest interests have never tried out the old ideas.

Foresters in Canada have become disenchanted with the facile formulae of forest finance. These formulae have shown themselves inapplicable to most of the day-to-day problems of woods operators in a logging economy. The result is that one of the best-known modern textbooks on forest economics has only one chapter on the subject, and a pretty vague chapter it is.

But today's pressure of competing uses for land puts the emphasis back on the older approaches. The older question was, in part: "How much can I afford to pay for a certain block of forest land?" The new question is similar: "How much is this land worth, in a forest use? Is it worth more or less than its alternative uses?"

Another change from the older circumstances is that the competing uses for land are constantly shifting. Municipal expansion and contraction, the ebb and flow of farm production, changing types of farming, the improvement and deterioration of local product transportation methods and evolving ideas about types of recreation create an ideal land use that is kaleidoscopic in its shifting pattern. The new problem for land-allocation decision is to keep abreast of these continual, random changes.

In the following paragraphs, I intend to develop the framework as it appears to economists concerned with the allocation of land among competing uses. But the reader should be warned that what I am doing is merely developing the need to estimate "soil rent" values for each of the competing uses of a certain unit of land.

\footnotetext{
${ }^{1}$ Professor, Department of Economics and Political Science, The University of British Columbia, Vancouver, B.C.
} 


\section{“Ideal" Land Allocation}

How to choose between competing uses of forest land might be an easy question in a "perfect" world. In such a world, we would have many small units of property, each privately owned. Each owner would be wellinformed about forestry, farming, mining, etc. He would make careful investigations of the carrying capacity of his land and the markets for each product. Then he would decide upon forestry, or farming, or some combination of the two. If all landlords did this, all land would be in its best use. The "problem" would not be a social problem at all.

In order to understand the real problem in Canada today, it is useful to see how it differs from this "perfect" model that I have just sketched.

(a) Landowners are not well-informed about the capacity of their holdings.

(b) They do not know much about the future market for farm or forest products.

(c) Most land is not privately owned, anyway, by landlords who are eagerly looking for its best use. Instead, there are huge blocks held by railways, governments, ranchers, loggers and industrial concerns.

It follows that to approximate the ideal result of the "perfect" world, we must follow a procedure which is at least analogous to it, though without its institutional trappings of widespread private ownership, etc.

We must start by dividing the land into workable area-units, each having uniform broad characteristics of fertility, drainage, climate, access to market, availability of labour, and so forth. Then we may study and allocate each to its best use, or uses.

As Mr. Brown's paper will have made clear, this first step is by no means easy. We know little yet about the various types of land that we have, physically or economically. Furthermore, we have the problem that the appropriate size of area for one use is not the same as for other uses, so that honest differences of opinion about land use arise merely from misunderstandings about the size of holding to be allocated.

I am not well qualified to discuss this problem, but I hope it will be properly dealt with in this panel's proceedings.

Assume, however, that we have settled on the unit of land. The question is, what is the best use for it? In the economists's framework, the answer is, simply, "choose the use that is most valuable."

\section{The Expected Net Yield Of Each Use}

To the private owner, the most valuable use is that which will bring him the most revenue, after all necessary costs. To the government owner, the most valuable use is that which will add most to the national product, (the annual stream of goods and services available for use of the people). To both of them, therefore, the most valuable use is that which brings in the greatest "net return". The word "net" here implies that the return consists of the revenues from the sales of the products of the land minus the costs required to earn that revenue, ( $\mathrm{I}$ stress this because many foresters talk about the revenues or the gross sales of forest products, neglecting to mention the costs in labour, capital and materials). 
So far, our economic framework consists of estimating the net yield from each use, and comparing them. Actually, we are looking for the future expected net yield from each competing use. This is more easily said than done. To find these for all the possible uses puts a heavy burden on the small store of "expectations" held by the average man.

First, the expected yields are in the future. Thus, in order to compare future flows of net return, they must be standardised, by discounting them all back to one date, presumably the present year. This procedure is familiar enough to foresters and engineers. The question is, what rate of interest should be used in the discounting?

The correct rate is discovered by looking at the problem from the point of view of the person, firm or authority who has to make the choice of land-use. This decision-maker must borrow funds at a certain rate of interest. Or he may lend at a certain rate. Or he may get a certain rate of return on his past successful investments. The highest of the rates at which he customarily does business is the relevant rate for discounting projects of equal risk. (This is intuitively obvious. There is no point in his investing for a return less than he can earn elsewhere, or less than he must pay to borrow funds).

Second, he must make the best possible estimate of the future market for the products of the alternative uses of his lands. For a farming use, for example, he must "take a view" on the possible price trends for all the crops and animals that his land might support, to find the best kind of farming. Then he must do his best to discover what the actual future prices are going to be, estimate his future flow of net revenue minus farming costs, and discount it back to the base date. This amounts to the farming equivalent of "soil rent", a familiar idea to foresters.

Third, the estimates of the competing expected net revenues must all be for the same future period of time. If the forestry project would stretch forward over eighty years, then the farming and other alternatives must also be worked out for this term.

Fourth, the assumptions about future business conditions, which affect our guesses about the future worth of wood products, must also be applied to the guesses about the future demand and price of farm products.

To summarize, we should make estimates of "soil rent" for each future use of the soil; we should make them comparable with respect to the rate of interest, term and future business conditions; then we should proceed to compare them. The use with the highest soil rent thus worked out should win the land from the conflicting uses.

\section{Combinations Of Uses: Multiple-Purposes}

It is not too early to point out that these "uses" need not be exclusive. In many parts of Canada we should expect to find that the best use is actually a combination of uses. In the first place, the soils expert may tell us that in spite of our best efforts to set up the land in homogeneous parcels, some parts of the unit is best adapted to tillage or pasture, some to wood production, some to recreation, some to transportation, and so 
forth. In other words, we must approach the optimum uses of the parcel by looking at the sub-optima for each sub-division.

In the second place, these competing uses are going to need labour, set up in establishments or enterprises. In order to make the best use of their time, in order to use some of their overhead capital efficiently, and in order to give their communities some diversity and stability, multiple uses of the local land may be desirable even in circumstances where the soil map is against it. Thus an area whose soil map indicates farming may well do better if the farmers also have forest employment; and forest communities may well prosper better when there is some farming also carried out.

In the third place, when our units to be allocated are very large, there will be demand for both wood and food, to be consumed locally.

For these three reasons, we should not confine ourselves to seeking the best single use of an area of land. We should begin with a general approach, that more than one use can flourish. Our problem is then to discover which combination, of which uses, is the best. (Note that it is possible that the best "combination" will turn out to have zero acres applied to all uses but one. In this circumstance, we would decide on a single use, rather than presume it from the outset.)

Actually, there are two kinds of combined use, both sometimes referred to as "multiple purpose forestry". In the first, different uses actually occupy adjoining divisions of the total area. In the second, the two uses are found on the same land. For example, the first might be arable farming in the middle of a large wooded area; while the second might be the pasturing of livestock right in the woods.

The second kind of combined use brings all the problems, for it really includes all cases where the carrying on of one use influences the general profitability of another, either favourably or adversely. Deciding on the combined use of the first kind is the easier of the two. It merely amounts to finding out how much farming net return is lost by contracting the area of farming and how much forestry net revenue is gained. This is called the incremental, or marginal, approach by economists. When the gain is greater than the loss, the farming area should be contracted and calculations then made to discover whether a further contraction would be advantageous. In this way, the best combination of farming and forestry acreage can be found, bringing in the largest net return for the entire acreage.

The second kind of combined use may be more difficult to determine. Little or no transfer of land between uses is contemplated. Instead, it is a question of how to obtain the largest net return from the entire area by (conceptually) experimenting with contractions in the intensity of each conflicting use. The reduced net return to the contracted use is to be compared with the increased net return to the remaining use. If there are more than two uses (e.g. if there is a possible combination of forestry, grazing and recreational uses) the number of alternative combinations becomes large. Further, it is possible that some intensities of some uses may benefit other uses, so that it becomes difficult to "converge" on the best combination. 
This is unfortunate. But, in general, the more difficult the exercise, the greater the gains from carrying it out; for it is unlikely that in such circumstances the best combination of uses would be arrived at by chance.

\section{Non-Marketable Uses Of Land}

For the wood-supply manager of the company and for the farmer this is about all that needs to be said. But speaking socially, society has other interests than the future prices and costs of the products of farm and forest. There are also non-marketed services of scenery, hunting, fishing, wildlife observation, watershed protection, ski-ing, pollution control, flood control, and so forth. The value of these services is often put aside, as "intangible". I agree that they are difficult to measure. But they are tangible enough; and they are important uses of the land. They are merely difficult to compare with the value of marketed, priced, commercial products.

The implication of their importance is that society must go to unusual trouble to make an estimate of their worth. They present two difficulties: first, they are not usually priced but are received free by their users; and second, they are not used individually but collectively. Therefore we must attempt to establish not merely what consumers would pay for them if they had to; but also that whole social groups (districts, provinces, nations) would pay rather than see them disappear or diminish.

Sometimes this can be done residually. This is the easier approach. We look at the more directly estimated soil rents of the competing uses, such as farming and forestry. Then we look at these "intangible" uses, and ask if their worth exceeds that of the marketable uses. The former give us a target figure that we must beat. We ask, "can this recreational use be worth $\$ 5$ million over the next thirty years?" And an answer may tumble out of the works quite directly.

But sometimes a direct estimate of intangible, unmarketed uses must be made. Then the decision-maker must settle down with a sharp pencil and ask what the use is worth to society. He may start by asking how much he could earn if he charged users for each visit. Then he might ask what he thinks local people might willingly pay in taxes in order to buy the land for a certain intangible use. Next he should look at the net income of local merchants (after all expenses) that can be directly attributed to the existence of the amenity. All of these estimates present practical and methodological traps for the man making the estimates. But they ought to be carried out. To the best of my knowledge, the literature of both farm and forest economics is almost bare of helpful discussions of the procedure.

Finally, it should be stressed again that the best use of land may be a combination of both marketed and "free" products. This is what many conservationists refer to as "true" multiple use. It should not be assumed in advance that multiple use is automatically a good thing. Some of the uses may conflict; the total soil rent of the land may be smaller in combined use than it is in a particular single use. The desirability of certain combinations as compared to certain single uses should emerge as a result of the calculations. 


\section{BENEFIT-COST ANALYSIS}

In Canada today, more and more is being said about benefit-cost (b/c) analysis. This type of approach has been applied primarily to water-resource uses, but of course it is of universal validity. It can apply to a stream, a forest, or to bare land.

But to foresters accustomed to the "soil rent" procedure, willing to apply it to all the competing uses of the land, there is actually nothing new in $b / c$ analysis. It uses the same data and will bring the user to the same conclusion.

In $b / c$ analysis, the question is: "Is it justifiable to change the use of this land to some other use?" For each conflicting or competing alternative, the benefits are estimated as a ratio to its costs. The benefits are the sum of the discounted future revenues, both marketed and non-marketed. The costs are all the expenses to be incurred in changing to and operating the new use. The ratio is called the "incremental b/c ratio." The change with the highest ratio wins the land. In this type of analysis, as in the "soil rent" approach, a good deal depends on deciding at the outset what is the appropriate size of land unit to be studied.

But I would like to stress two matters that I have touched on already.

First, all alternatives must be considered. By this I mean that the values of other social (recreation, aesthetic, etc.) uses and other private (farming, residential) uses must both be taken into account. The decision-maker is here trying to make the best use of land, not to find the best way of growing trees. The land must never be assumed in advance to be best suited for any particular purpose. Indeed it should not be assumed in advance to have any use at all!

Second, the time dimension in the consideration of alternatives must be kept comparable. If by any chance perpetual-yield forestry is contemplated, then the use of the land must be compared with the gains of perpetual agriculture in the same location. Similarly, just as various types of agriculture must be considered, so various regimes of forestry must be investigated, from perpetual yield at one extreme to cut-and-get-out at the other extreme.

These two reminders apply both to the net-return approach and to the benefit cost approach.

\section{CONClusion: A ReProach TO Forestry}

For trained foresters, none of what I have been saying is very new or surprising. What is remarkable is that none of this kind of analysis is ever carried out. Canadians are as apathetic about making good decisions about the use of their lands as they are about the use of their waters. They are willing to carry in their minds immense volumes of information about the standings of football teams, about the total gate at boxing matches, and about the number of people who listen to television stations. But, faced with the threat of figures about natural resources and their uses, they flinch and mutter apologies about the complexity and technicalities involved. 
This is our fault. These ideas are no more difficult than are batting averages or league standings. But we have failed to apply them rigorously or advance them beyond the ambitions of nineteenth century pioneers. When we have produced data, they have been so qualified and refutable that the audience has melted away.

It is also the government's fault. Rarely or never does the government call for quantified estimates of the value of competing uses. Royal Commissions accept as evidence the most ill-prepared briefs of ill-informed special pleaders. It is laughable to compare the accurate and standardised specifications of government purchase orders, designed to save a few hundreds of dollars with the vague, broad and loose systems of disposal and transfer of government lands. Usually, indeed, numbers do not come into the disposal at all.

Foresters have the longest tradition of a system of economics in which valuation plays a large part. Why have they been so loath to understand it themselves, and to place its conclusions before tribunals? No new frameworks for allocation are needed. In the traditional methods of forest finance, expanded and sharpened, are the tools for the best allocation of land between competing uses. 